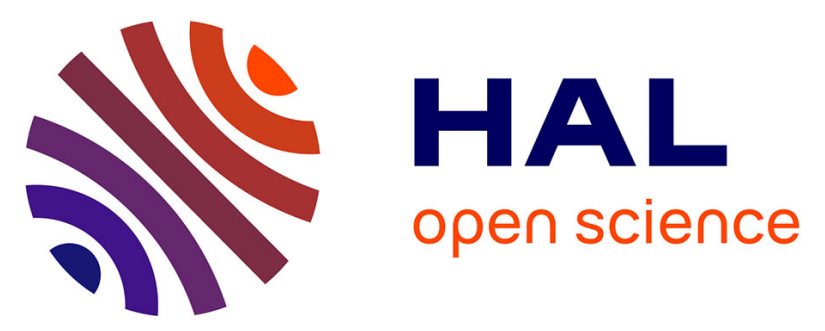

\title{
A chemical speciation insight into the palladium(ii) uptake and metabolism by Sinapis alba. Exposure to Pd induces the synthesis of a Pd-histidine complex
}

Katarzyna Kińska, Katarzyna Bierla, Beata Krasnodębska-Ostręga, Simon Godin, Joanna Kowalska, Hugues Preud'Homme, Ryszard Lobinski, Joanna

Szpunar

\section{To cite this version:}

Katarzyna Kińska, Katarzyna Bierla, Beata Krasnodębska-Ostręga, Simon Godin, Joanna Kowalska, et al.. A chemical speciation insight into the palladium(ii) uptake and metabolism by Sinapis alba. Exposure to Pd induces the synthesis of a Pd-histidine complex. Metallomics, 2019, 11 (9), pp.1498

- 1505. 10.1039/c9mt00126c . hal-03133522

\author{
HAL Id: hal-03133522 \\ https://hal.science/hal-03133522
}

Submitted on 18 Feb 2021

HAL is a multi-disciplinary open access archive for the deposit and dissemination of scientific research documents, whether they are published or not. The documents may come from teaching and research institutions in France or abroad, or from public or private research centers.
L'archive ouverte pluridisciplinaire HAL, est destinée au dépôt et à la diffusion de documents scientifiques de niveau recherche, publiés ou non, émanant des établissements d'enseignement et de recherche français ou étrangers, des laboratoires publics ou privés. 
Received 00th January 20xx, Accepted 00th January 20xx

DOI: $10.1039 / \times 0 x \times 00000 x$

\title{
A chemical speciation insight into the palladium nanoparticle uptake and metabolism by Sinapis alba. Exposure to Pd induces the synthesis of a Pd-histidine complex
}

\author{
Katarzyna Kińska, ${ }^{a, b}$, Katarzyna Bierlab ${ }^{b}$ Simon Godin ${ }^{b}$, Hugues Preud'hommes ${ }^{b}$, Joanna Kowalskaa, \\ Beata Krasnodębska-Ostręga ${ }^{a}$, Ryszard Lobinski ${ }^{b}$, Joanna Szpunar ${ }^{\text {b* }}$
}

\begin{abstract}
Palladium is recognized as a technologically critical element (TCE) because of its massive use in automobile exhaust gas catalytic converters. The release of Pd into the environment in the form of nanoparticles of various size and chemical composition requires the understanding of their metabolism by leaving organisms. We provide here for the first time a chemical speciation insight into the identity of the ligands produced or used by a plant Sinapis alba L. exposed in hydropony to Pd nanoparticles and soluble Pd (nitrate). The analytical method developed was based on the concept of 2D HPLC with parallel inductively coupled plasma mass spectrometry (ICP MS) and electrospray MS detection. Size exclusion chromatography - ICP MS of the plant extracts showed no difference between the speciation of Pd after the exposure to nanoparticles and after that to $\mathrm{Pd}^{2+}$ which indicated the reactivity and dissolution of $\mathrm{Pd}$ nanoparticles. A comparative investigation of the Pd speciation in a control plant extract spiked with $\mathrm{Pd}^{2+}$ and of an extract of a plant having metabolized palladium indicated the response of the Sinapis alba by the formation of a Pd-histidine complex. The complex was identified by Orbitrap MS; the HPLC-MS chromatogram produced two peaks at $\mathrm{m} / \mathrm{z} 415.0341$ each corresponding to a Pd-His 2 complex. An investigation by ion-mobility MS revealed a difference in their collision cross section indicating that the complexes present varied in terms of spatial conformation. A number of other Pd complexes with different ligands (including nicotianamine) circulating in the plant were detected by but these ligands were already observed in a control plant and their concentrations were not affected by the exposure to Pd.
\end{abstract}

\section{Introduction}

The increasing emission of platinum group elements (PGEs), resulting from their use in catalytic converters, is reflected in their growing accumulation in the environment. ${ }^{1}$ PGEs are released into environment at a rate up to $200 \mathrm{ng} \mathrm{km}^{-1}$ per car, mostly as metal or metal oxide nanoparticles, mainly due to high thermochemical stress of the catalysts and mechanical abrasion. ${ }^{2}$ The highest emission is observed for palladium, the use of which has increased significantly in last decades. Consequently, Pd concentrations in roadside soil reaching up to $700 \mu \mathrm{g} \mathrm{kg}^{-1}$ were reported. ${ }^{3}$ The mobility and bioavailability of $\mathrm{Pd}$ are significantly higher than those of other platinum group metals. ${ }^{4}$ Palladium can be taken up fairly easily by plants and small organisms. ${ }^{5}$

Plants, situated at a low level of the food chain, play a key role in the metal (ionic and nanoparticle) cycling in the environment which raises interest in the mechanisms of the metal uptake, translocation, bioaccumulation and detoxification. ${ }^{6,7}$ Organic ligands present in plant sap or bio-synthetized in roots and shoots play an important role in these processes. From the chemical point of view, these

a. Faculty of Chemistry, University of Warsaw, Pasteura 1, 02-093 Warsaw, Poland. b. Institute of Analytical and Physical Chemistry for the Environment and Materials, IPREM, UMR 5254 CNRS-UPPA, Hélioparc, Pau, France

Electronic Supplementary Information (ESI) available. See DOI: 10.1039/x0xx00000x ligands can be divided into three classes, depending on which of the atoms donates an electron pair: sulfur (metallothioneins and phytochelatins), nitrogen (amino acids), or oxygen (as carboxylates, malate, citrate, malonate, succinate or oxalate. ${ }^{8}$ In plants, the most common ligands involved in the transport and storage of metals ions include cysteine, histidine, nicotianamine, malate or citrate. ${ }^{9-11}$ Therefore, speciation of metals in plants is of utmost importance. The recent review on speciation of technologically critical elements indicates the scarcity of data on the speciation of PGEs in plants. ${ }^{12}$ In particular for palladium, the only information available was obtained by the fractionation of a water soluble Pd fraction showing three complexes, accounting for $\mathrm{ca}$. $7 \%$ of Pd, which were not identified. ${ }^{13}$ Our previous work demonstrated the uptake of Pd nanoparticles and their translocation to root and shoots of an edible plant (Sinapis alba L. or white mustard) associated with a decrease of particle size and their putative solubilization. ${ }^{14}$ The goal of this research was two-fold: (i) to obtain an insight into the molecular mechanisms of the reactivity of the $\mathrm{Pd}$ nanoparticles by identifying ligands able to dissolve Pd and to allow its transport into shoots and leaves, and (ii) testing the hypothesis that there exists a mechanisms of synthesis of a bioligand as a response mechanism of Sinapis alba L. against Pd. Palladium is known to form stable complexes with a number of organic ligands, but none of them has been identified in a plant tissue yet. ${ }^{15-17}$

In order to achieve the Pd speciation analysis, the concept of 2D HPLC with parallel ICP MS and electrospray MS detection proposed 
elsewhere was revisited and tailored to provide molecular information on Pd species. ${ }^{18}$ First, size-exclusion chromatography was optimized in order to allow the molecular-size fractionation of the totality of the soluble Pd present resulting in a metallomics approach (targeting all the soluble forms of a metal (Pd) present). ${ }^{19}$ Then, the fraction of interest was probed by hydrophilic ion interaction liquid chromatography (HILIC) with the parallel detection by ICP MS and Orbitrap MS/MS to identify the species present. ${ }^{20-22}$ In addition, we explored for the first-time the spatial conformations of the produced species by ion-mobility MS.

\section{Experimental}

Reagents, standards, and solutions.

Analytical reagent grade and LC MS grade reagents used during the studies were acquired from Sigma-Aldrich (Saint Quentin Fallavier, France) unless stated otherwise. Ultrapure water $(18 \mathrm{M} \Omega \mathrm{cm})$ used during the studies was obtained from Milli-Q system (Millipore, Guyancourt, France). Aqua regia was produced by mixing (3:1 v/v) concentrated $\mathrm{HCl}$ and $\mathrm{HNO} 3$ of Ultranal quality (Cheman, www.ciechtrading.com). Palladium (II) standard stock solution was diluted up to $1.9 \mu \mathrm{mol} \mathrm{L-1}$ and mixed with series of ligands solutions $(3.8 \mu \mathrm{mol}$ L-1) in ratio 1:1. After appropriate dilution a total palladium concentration of $0.24 \mu \mathrm{mol} \mathrm{L}-1$ was introduced onto ZIC HILIC column as mixtures with: cysteine, glycine, histidine, methionine, nicotianamine and glutathione.

\section{Instrumentation.}

Wet digestion was carried out in a closed, microwave assisted Ethos 1 system (Milestone, www.milestonesrl.com), Size exclusion chromatography (SEC) separations were carried out on Superdex 200 (separation range: 10,000-600,000 Da) and Superdex Peptide 300 (separation range: $100-7,000 \mathrm{Da}$ ) columns (GE Healthcare, www3.gehealthcare.com), with a 1200 HPLC system (Agilent, www.agilent.com) equipped with an autosampler. Hydrophilic interaction chromatography was performed on a SeQuant ${ }^{\oplus} \mathrm{Zic}^{\circledR}$. cHILIC (150 x $2.1 \mathrm{~mm}, 3 \mu \mathrm{m}$ 100Å) column (Merck,) and Kinetex HILIC $(150 \times 2,1 \mu \mathrm{mm}, 2,6 \mu \mathrm{m}$ 100Å) column (Phenomenex, www.phenomenex.com). The metal elution was monitored by a 7500 or 7700 ICP-MS (Agilent) connected directly to the column outlet. For HPLC-MS/MS analysis, a Dionex system (Ultimate 3000RS) was coupled to an Orbitrap Fusion ${ }^{\mathrm{TM}}$ Lumos $^{\mathrm{TM}}$ Tribrid $^{\mathrm{TM}}$ Mass Spectrometer (Thermo Scientific, www.thermofisher.com). The ionmobility instrument was timsTOF from Bruker (Bruker Daltonics, Bremen, Germany) coupled to an ACQUITY UPLC system (Elstree, UK).

\section{Hydroponic cultivation.}

The plants Sinapis alba L. were cultivated for a period of 4 weeks in a growth chamber as described elsewhere. ${ }^{23}$ Firstly Sinapis alba were seeded in artificial substrate (glass balls). At the cotyledon stage seedlings were transplanted into $4 \mathrm{~L}$ pots (9 plants per pot) containing Knop's nutrient solution. After two weeks of uninterrupted growth, nutrient solution was spiked with an aqueous solution of $\mathrm{Pd}\left(\mathrm{NO}_{3}\right)_{2}$ or suspension of PdNPs in $2 \mathrm{mmol} \mathrm{L}^{-1}$ citrate buffer, to reach a final Pd concentration of $1.0 \mathrm{mg} \mathrm{L}^{-1}$. Control plants were cultivated in parallel. The cultivations were continued for two more weeks. Then, the plants were harvested and weighed. Once divided into leaves, stems and roots, the plants tissues were submitted immediately to the extraction procedure or were air dried and homogenized in agate ball mill (www.fritsch-international.com).

\section{Extraction of $\mathbf{P d}$ compounds from plant material.}

A $1 \mathrm{~g}$ sample of fresh plant leaves, stems and roots was grinded in a mortar in the presence of liquid nitrogen. Homogenized material was afterwards extracted with $3 \mathrm{ml}$ (leaves/stems) or $6 \mathrm{~mL}$ (roots) of water at $1^{\circ} \mathrm{C}$ for $90 \mathrm{~min}$. Simultaneous extractions were carried out for control plant organs and control plant material spiked with $\mathrm{Pd}\left(\mathrm{NO}_{3}\right)_{2}$. After the extraction was complete, the samples were centrifuged. The supernatants were separated from the residues, transferred to smaller containers and lyophilized. Prior to analysis, the lyophilized extracts were dissolved in water. After $90 \mathrm{~min}$ of shaking in ambient temperature, samples were centrifuged for $5 \mathrm{~min}$ (3000 rpm), and supernatants were analyzed immediately. For air dried samples, a sample of $200 \mathrm{mg}$ of homogenized roots, stems or leaves was extracted with $1.5 \mathrm{~mL}$ of water at room temperature for $1 \mathrm{~h}$. Then, the mixture was centrifuged for $5 \mathrm{~min}$ (3000 rpf) and the obtained supernatant was analyzed immediately.

\section{Determination of the total Pd concentration.}

A sample $(50-100 \mathrm{mg})$ was digested in $3.0 \mathrm{~mL}$ aqua regia. Digestion was carried out according to the temperature program: $0-5 \mathrm{~min}$ to $90^{\circ} \mathrm{C}, 5-15 \mathrm{~min}$ to $170^{\circ} \mathrm{C}, 15-75 \mathrm{~min}$ to $200^{\circ} \mathrm{C}$. After the end of the digestion process, the obtained solution was quantitatively transferred and diluted with water to $10 \mathrm{~mL}$. Total Pd content was determined by ICP MS, the isotopes ${ }^{105} \mathrm{Pd},{ }^{106} \mathrm{Pd}$ and ${ }^{108} \mathrm{Pd}$ were simultaneously monitored and the quantitative determination was carried out using a calibration curve. The RF power was $1600 \mathrm{~W}$ and deflector voltage $-9 \mathrm{~V}$. The flow rates of the nebulizer, plasma and auxiliary gases were $1.0,18.0$ and $1.2 \mathrm{~L} \mathrm{~min}^{-1}$, respectively.

\section{Chromatographic separations.}

The extracts were diluted 10 -fold. Injection volume was $100 \mu \mathrm{L}$. SEC separation was performed isocratically $\left(0.7 \mathrm{~mL} \mathrm{~min}^{-1}\right)$ with $100 \mathrm{mmol} \mathrm{L}^{-1}$ ammonium acetate $(\mathrm{pH} 7.5)$ as a mobile phase. For HILIC analysis, samples were diluted 1:1 with acetonitrile. Two types of HILIC columns were used. To separate compounds on SeQuant ${ }^{\circledR} \mathrm{Zic}^{\circledR}$-cHILIC the mobile phase was a mixture of $5 \mathrm{mmol} \mathrm{L}^{-1}$ ammonium acetate and acetonitrile in a gradient: $0 \mathrm{~min}-100 \% \mathrm{~B}$; $2.5 \mathrm{~min}-100 \%$ B; $27 \mathrm{~min}-65 \%$ B; $35 \mathrm{~min}-60 \%$ B; $36 \mathrm{~min}-100 \%$ B; $46 \mathrm{~min}-100 \% \mathrm{~B}$ where $A$ was $10 \% 5 \mathrm{mmol} \mathrm{L}^{-1}$ ammonium acetate $(\mathrm{pH}$ $5.5)+80 \% \mathrm{H}_{2} \mathrm{O}+10 \%$ acetonitrile (ACN), while B was $10 \% 5 \mathrm{mmol} \mathrm{L}^{-}$ ${ }^{1}$ ammonium acetate $(\mathrm{pH} 5.5)+90 \% \mathrm{ACN} .4 \mu \mathrm{L}$ of injected sample was separated in a $200 \mu \mathrm{L} \mathrm{min}^{-1}$ flow rate. To separate compounds on Kinetex HILIC, as a mobile phase $25 \mathrm{mmol} / \mathrm{L}$, pH 5.5 ammonium acetate (A) and ACN (B) were use in gradient: 0 min - 95\% $B ; 1$ min $95 \%$ B; $10 \min -80 \%$ B; 13.5 min - 60\% B; 17 min - 60\% B; 21 min $60 \% \mathrm{~B}, 30 \mathrm{~min}-95 \%$ B. $20 \mu \mathrm{L}$ of injected sample was separated in a $0.5 \mathrm{~mL} \mathrm{~min}^{-1}$ flow rate.

\section{ICP MS detection.}

The conditions were as described above. The chromatographic traces were presented for the ${ }^{104} \mathrm{Pd}$ isotope (11.14\% abundance). 


\section{Orbitrap MS detection.}

The instrument was operated in the positive ionization mode at a 240000 resolution. The electrospray voltage was set to $3.5 \mathrm{kV}$, the ion transfer tube temperature to $325^{\circ} \mathrm{C}$ and the vaporizer temperature to $150^{\circ} \mathrm{C}$. The sheath gas and auxiliary gas were set to 35 and 10 units, respectively. The mass spectrum registered in the mass range $50-1000 \mathrm{~m} / \mathrm{z}$ was searched for parent ions with an isotopic pattern characteristic for $\mathrm{Pd}\left(5\right.$ main isotopes: ${ }^{104} \mathrm{Pd},{ }^{105} \mathrm{Pd}$, ${ }^{106} \mathrm{Pd}$, ${ }^{108} \mathrm{Pd}$, and ${ }^{110} \mathrm{Pd}$ with abundancies of $11.14,22.33,27.33,26.46$ and $11.72 \%$, respectively. The search for Pd isotopic patterns in mass spectra was carried out using Compound Discoverer software program. The mass tolerance was set to $5 \mathrm{ppm}$ and the intensity tolerance to $30 \%$. For MS/MS analysis, collision energy was 30 $35 \mathrm{kV}$.

\section{Ion mobility (TIMS TOF) detection.}

Samples were ionized using a standard ESI source (Bruker Daltonics, Champs sur Marne, France) in positive mode. The operating conditions were $4500 \mathrm{~V}$ as capillary voltage, $-500 \mathrm{~V}$ as end plate, 2.5 bars nebulizer pressure, $6.0 \mathrm{~L} \mathrm{~min}^{-1}$ dry gas and the dry heater set at $200^{\circ} \mathrm{C}$. The mass range was set from 150 to $1350 \mathrm{~m} / \mathrm{z}$. The TIMS was set in detect mode with a $1 / \mathrm{k} 0$ range from 0.45 to $1.55 \mathrm{~V} \mathrm{~s} \mathrm{~cm}^{-2}$. The acquisition rate was $2,86 \mathrm{~Hz}$. The IMS service ramp of $70 \mathrm{~ms}$, the IMS tunnel voltage Delta 1 of $-20 \mathrm{~V}$ and delta 2 at $-120 \mathrm{~V}$ were used. The TOF and TIMS calibrations were performed by infusing at $5 \mu \mathrm{L} \mathrm{min}^{-1}$, a ESI-TOF tuning mix calibration standard solution from Agilent (Les Ulis, France).

\section{Results and discussion}

\section{The growth of Sinapis alba L.in the presence of palladium}

No significant morphological changes were observed when comparing the plant growth with and without Pd addition, regardless of its form (soluble or nanoparticles). However, it was observed that the average stem length of plants cultivated in the presence of $\mathrm{Pd}$ salt was by $13 \%$ higher than in control plants, while the root length was $19 \%$ lower. A similar observation was reported by Ronchini et al. in roots of Pisum sativum exposed to $1 \mathrm{mg} \mathrm{L}^{-1} \mathrm{~K}_{2} \mathrm{PdCl}_{4}$, the stems also had a slightly reduced length. ${ }^{24} \mathrm{~A}$ significant decrease of the leaves length was also observed in barley cultivated in the presence of 1 $12 \mathrm{~nm}$ Pd nanoparticles. ${ }^{25}$ The average biomass of white mustard cultivated with Pd addition was about $20 \%$ lower compare to the control conditions. In terms of percentage, the most noticeable decrease in biomass was observed for roots, which was in line with the observed reduced average root length. In the case of Pisum sativum, the decrease in roots biomass production was not observed until the concentration of palladium reached $10 \mathrm{mg} \mathrm{L}^{-1} .{ }^{24}$

The above observations lead to the conclusion that plants grown in the presence of $\mathrm{Pd}$ show an increase in the stem length and inhibition of root growth. This, together with the lower biomass, is indicative of plant weakness and toxicity of $\mathrm{Pd}$ at the investigated concentration levels.

\section{Palladium uptake and molecular mass Pd-species distribution}

Regardless whether Pd was provided in the form of nanoparticles or dissolved $\left[\mathrm{Pd}\left(\mathrm{NO}_{3}\right)_{2}\right]$, it concentrated in plant roots at 638-694 and 919-932 $\mathrm{g} \mathrm{g} \mathrm{g}^{-1}$ (dry weight), respectively. The values measured in leaves $\left(0.21 \pm 0.1\right.$ and $0.28 \pm 0.02 \mu \mathrm{g} \mathrm{g}^{-1}$, dry weight, respectively) and stem $\left(0.18 \pm 0.01\right.$ and $0.17 \pm 0.01 \mu \mathrm{g} \mathrm{g}^{-1}$, dry weight, respectively), were much lower. Moreover, in plants cultivated with $\mathrm{Pd}$ nanoparticles about $7 \%$ of Pd in Sinapis alba roots, $21 \%$ in stems and $28 \%$ in leaves was present in dissolved form (inset to Fig. 1). ${ }^{14}$

Fig. 1 shows that the morphology of the size-exclusion ICP MS chromatogram (distribution of Pd among the molecular species as a function of the molecular mass) is identical regardless of the supplied form. The chromatogram of the control samples shows no contamination from the laboratory conditions. Even if interactions of the stationary phase may considerably affect the retention of the Pdcomplexes in the molecular sieve, it can be said that most of palladium is present as low molecular weight complexes $(<10 \mathrm{kDa})$. Alt and Weber showed that equal amounts of soluble palladium compounds in Lactuca sativa L. and Cichorium endivia var. crispum are were present as high $(160 \mathrm{kDa})$ and low molecular weight ( $<10 \mathrm{kDa}$ ) species. ${ }^{26,27}$ Low molecular weight complexes had not been further studied. Leśniewska et al showed that Pd was strongly retained in roots but ca. $10 \%$ was transported to leaves and metabolized; the water soluble fraction contained ca. $70 \%$ of $\mathrm{Pd} .{ }^{13}$ The lower molecular mass fraction $(<10 \mathrm{kDa})$ studied by SEC (exclusion limit 3,000 Da) with ICP MS detection indicated the presence of at least three peaks, but the species could not be identified. ${ }^{13}$

Note that the chromatogram corresponding to the plant exposed to Pd-nanoparticles is less intense as only $7 \%$ palladium (Fig. 1, inset) was dissolved and could be chromatographed. The morphologies of the chromatograms of the extracts of the plants exposed to nanoparticles and to dissolved palladium were similar. Consequently, the subsequent identification studies were carried out on the extracts of Sinapis alba grown in the presence of $\mathrm{Pd}\left(\mathrm{NO}_{3}\right)_{2}$ which contained higher concentrations of the soluble Pd-containing compounds.

Chromatograms of fresh root extracts after lyophilization and extract of dried plant material were compared (Fig. SI 1). The chromatograms show peaks of similar retention times, but subtle differences in the chromatogram morphology are observed.

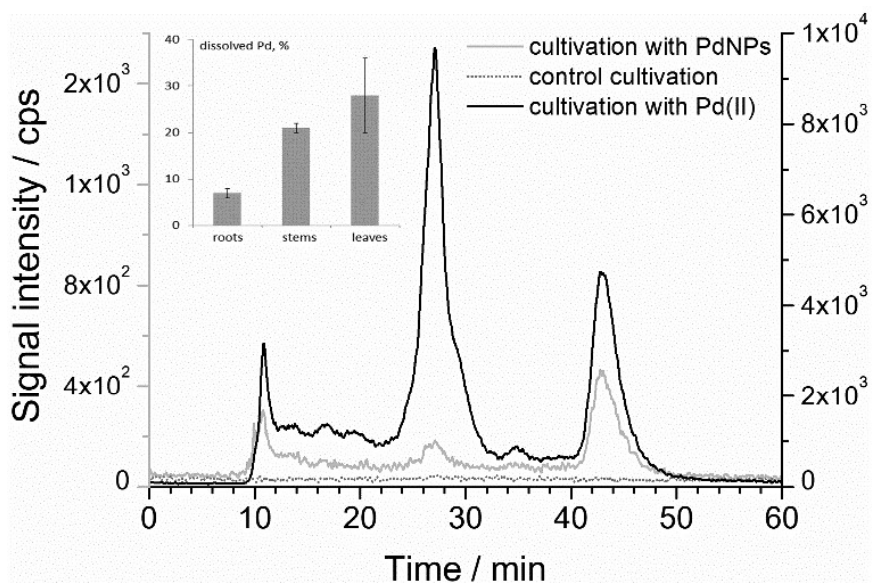

Figure 1. SEC ICP MS chromatograms of Sinapis alba root extracts from the control cultivation (grey dotted line) and in the presence of PdNPs (light grey line) and $\mathrm{Pd}\left(\mathrm{NO}_{3}\right)_{2}$ (black line; auxiliary axis). Chromatograms were obtained using a SEC Superdex Peptide column after injection of $100 \mu \mathrm{L}$ of the sample and isocratic elution with ammonium acetate $(\mathrm{pH} 7.5)$ at a flow rate of $0.7 \mathrm{~mL} \mathrm{~min}^{-1}$. The inset shows the percentage of $\mathrm{Pd}$ dissolved as the results of the NP-Pd uptake. 
Nevertheless, regardless of the plant material preparation, the most intensive peak is eluted in time 25-30 min, which remains stable after lyophilization. Further work was carried out upon the extraction of dried tissues.

Fig. 2 compares the molecular size distribution of Pd in roots, stems and leaves. It shows a strong difference in the mass distribution of the Pd-species as a function of the plant tissue with a noticeable transport of part of the palladium species found in root to stems and leaves. Nevertheless, there exist large molecular mass palladium species (high molecular mass fraction) which are not transported to the upper parts. Also, the presence of a peak at $40 \mathrm{~min}$, putatively assigned as $\mathrm{Pd}^{2+}$ indicates the need for specific ligands to assure the transport of palladium towards the upper plants of the plant.

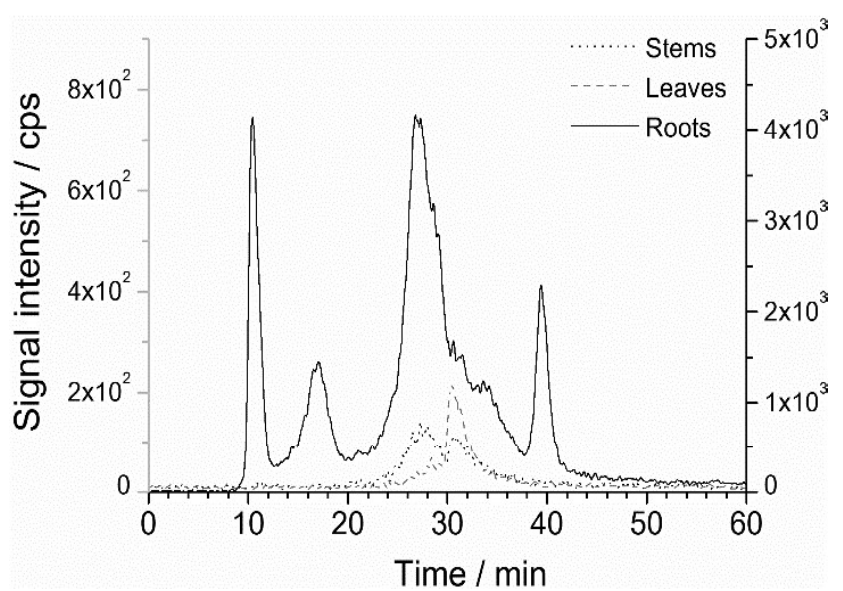

Figure 2. SEC ICP MS chromatograms of extracts of leaves (light grey dashed line), stems (black dotted line) and roots (black solid line; auxiliary axis) of Sinapis alba grown in the presence of $\mathrm{Pd}\left(\mathrm{NO}_{3}\right)_{2}$. Chromatograms were obtained using a SEC Superdex-200 column after injection of $100 \mu \mathrm{L}$ of the sample, isocratic elution with ammonium acetate ( $\mathrm{pH} 7.5$ ) at a flow rate of $0.7 \mathrm{~mL} \mathrm{~min} \mathrm{~m}^{-1}$.

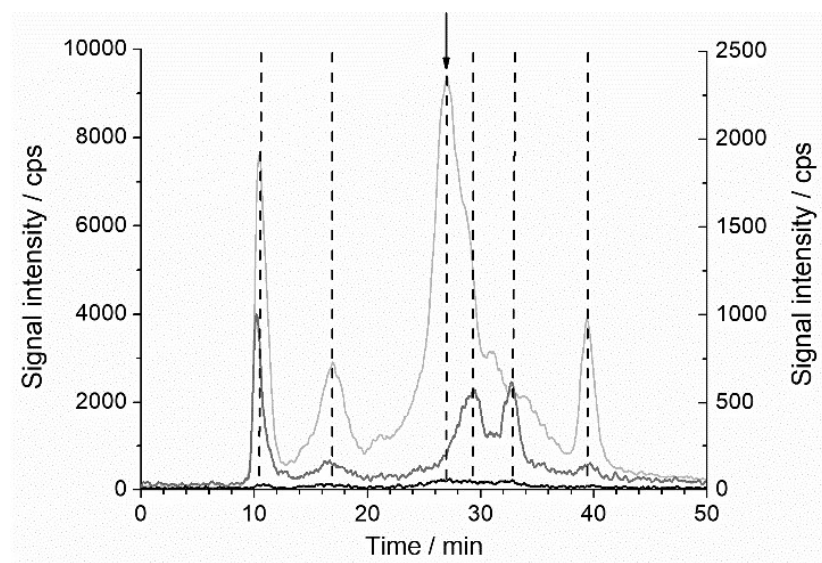

Figure 3. SEC ICP MS chromatograms of an extract of roots of Sinapis alba: control plant (cultivated with no contact with $\mathrm{Pd}$ (bold black line), cultivated in the presence of $\mathrm{Pd}\left(\mathrm{NO}_{3}\right)_{2}$ (light grey line; left axis), blank sample spiked with $\mathrm{Pd}\left(\mathrm{NO}_{3}\right)_{2}$ (grey line) Chromatograms were obtained using a SEC Superdex-200 column after injection of $100 \mu \mathrm{L}$ of the sample and isocratic elution with ammonium acetate $(\mathrm{pH} 7.5)$ at a

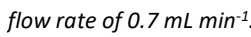

\section{Identification of the Pd-binding ligands biosynthesized as a function}

\section{of exposure to Pd stress}

A plant extract contains a number of ligands which are able to complex palladium. However, no palladium complex has ever been identified in plants yet. More important is to verify whether an exposure of a plant to Pd stress triggers off the synthesis of specific ligands as a mechanism of the plant detoxification. Therefore and experiment was designed to verify such a hypothesis.

For this purpose a size-exclusion chromatogram of a sample of a control plant extract spiked with $\mathrm{Pd}^{2+}$ was compared with that of a plant extract cultivated in the presence of $\mathrm{Pd}\left(\mathrm{NO}_{3}\right)_{2}$. (Fig. 3). Most of peaks are common to both chromatograms. Interestingly, the most intense peak corresponding to the Pd complex is present only in the extract of plant cultivated in the presence of $\mathrm{Pd}\left(\mathrm{NO}_{3}\right)_{2}$. Further work aimed at the identification of this biosynthesized compound.

\section{Identification of the biosynthesized palladium complex}

The fraction corresponding to the peak of interest was collected and reinjected onto the SEC column to check the stability of the palladium species in view of their further analysis by another chromatographic mechanism (Fig. $2 \mathrm{SI}$ ). The retention time and the intensity of the peak were preserved which indicates the stability of the complex.

The identification of the Pd-complex was carried out by HILIC electrospray MS/MS. The choice of HILIC, introduced for speciation analysis of metal complexes by Ouerdane et al. ${ }^{22}$, was dictated by its suitability for small polar compounds as amino acids, peptides and proteins and the compatibility of the mobile phase conditions with electrospray mass spectrometry. ${ }^{28}$ Two types of column: SeQuant ${ }^{\circledR}$ Zic $^{\circledR}$-cHILIC and Kinetex HILIC were investigated. Both columns applied were of the same length, internal diameter and the pore size. As stationary phase, the unbonded silica is applied in Kinetex column, while ZIC involves the bonding of zwitterionic phosphorylcholine functional groups to a silica backbone of the stationary phase. Following the optimization of $\mathrm{pH}$ and mobile phase gradient conditions a more efficient fractionation (Fig. $3 \mathrm{SI}$ ) was obtained using the ZIC column which was use for the further study. The optimized conditions proved to be suitable for the separation of most of Pd complexes with ligands expected to occur in a plant: glutathione, histidine, cysteine, glycine, methionine and nicotianamine produce sharp well defined peaks in the optimum separation conditions (Fig. $4 \mathrm{SI}$ ).

A HILIC-ICPMS chromatogram of the fraction corresponding to the biosynthesized compound is shown in Fig. 4A. It contains 6 peaks corresponding to $\mathrm{Pd}$ compounds. A chromatogram obtained for the control extract spiked with $\mathrm{Pd}^{2+}$ (Fig. 4B) shows that three of these ligands were present in the control sample, and therefore showed limited interest. A chromatogram obtained in the same separation conditions as that in Fig. 5a but using electrospray Orbitrap MS detection showed two compounds with the Pd isotopic pattern at $\mathrm{m} / \mathrm{z} 408.038$ and $\mathrm{m} / \mathrm{z}$ 415.034. Extracted ion chromatograms (XICs) corresponding to these ions are presented in Fig. 4C-D. Both XICs show presence of multiple peaks: three or four for the $m / z 408.038$ ion and two for the $m / z 415.034$ ion. In order to obtain information on putative structures, the ions obtained were submitted to 


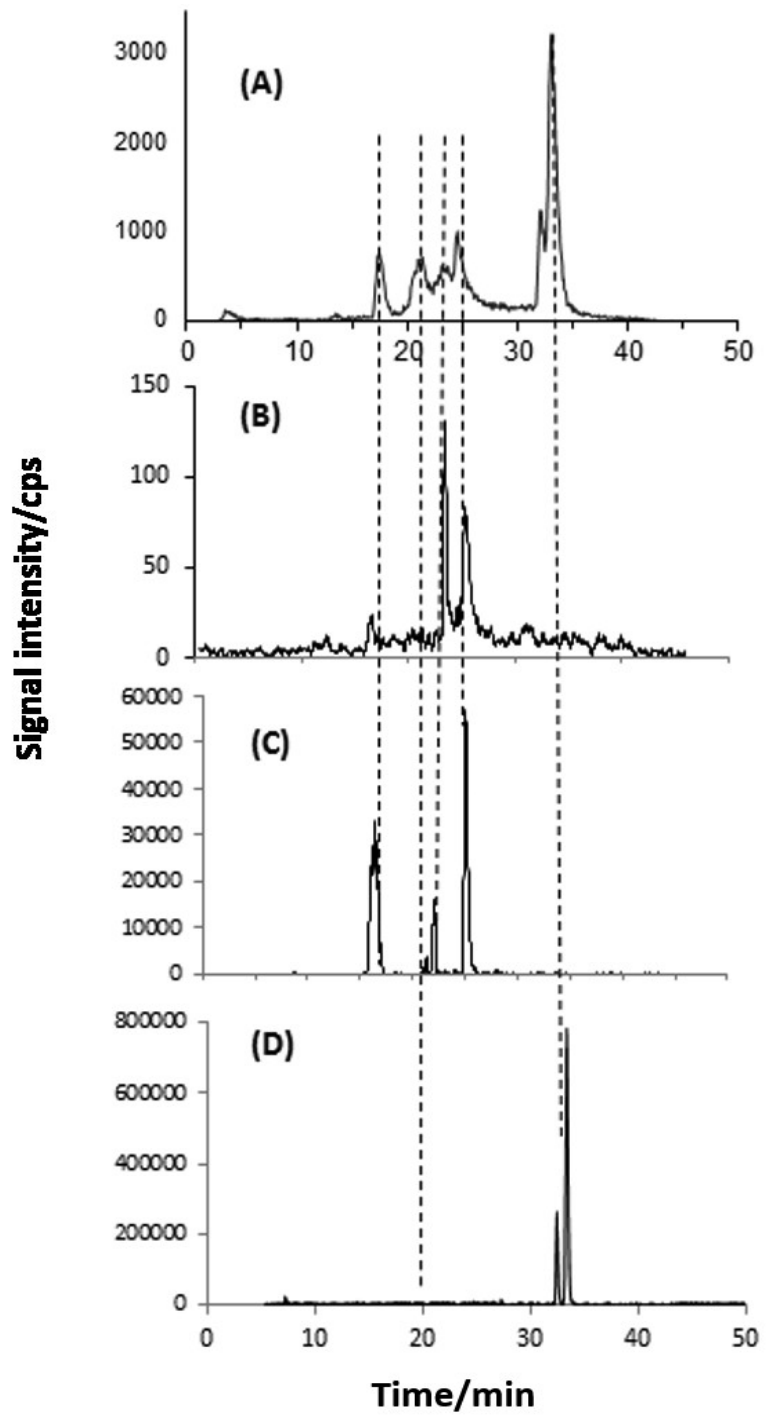

Figure 4. HILIC chromatograms of the fraction of root extract of Sinapis alba: A) extract of plant grown in the presence of $\mathrm{Pd}\left(\mathrm{NO}_{3}\right)_{2}$ and then fractionated by SEC (ICP MS detection); $\mathrm{B}$ ) extract of control plant spiked with $\mathrm{Pd}\left(\mathrm{NO}_{3}\right)_{2}$ and then fractionated (ICP MS detection); C) extract of plant grown in the presence of $\mathrm{Pd}\left(\mathrm{NO}_{3}\right)_{2}$ and then fractionated by SEC (XIC corresponding to $\mathrm{m} / \mathrm{z}$ 408.03814, ESI Orbitrap MS detection);

D) extract of plant grown in the presence of $\mathrm{Pd}\left(\mathrm{NO}_{3}\right)_{2}$ and then fractionated by SEC (XIC corresponding to $\mathrm{m} / \mathrm{z}$ 415.03406, ESI Orbitrap MS detection).

fragmentation. The fragmentation data are presented in Fig. 5; in most cases the mass accuracy was at the $1 \mathrm{ppm}$ level.

Fig. 5 summarizes the fragmentation pathways of the identified compounds. The identity of the species: Pd-nicotianamine and Pd$\mathrm{His}_{2}$ was confirmed by HILIC- ESI MS ${ }^{n}$ analysis of the synthetic standards. An additional confirmation was obtained by the negative ionization ESI $\mathrm{MS}^{n}$ analysis although fewer fragment ions were observed. The detection of the nicotianamine- characteristic $\mathrm{m} / \mathrm{z}$ values at the different retention time indicates the presence of larger nicotianamine containing Pd-binding ligands which are dissociated in the ionization source.
$\mathrm{Pd}-\mathrm{His}_{2}$ complex is the main Pd species produced by Sinapis alba $\mathrm{L}$.

\section{upon exposure to PdNPs or $\mathbf{P d}^{2+}$ ions}

The main finding is the identification of the $\mathrm{Pd}-\mathrm{His}_{2}$ complex which accounts for the majority of palladium (40\% estimated from the peaks' area in the chromatogram) complexed by histidine synthetized during the exposure to Pd. The Pd-histidine complex produces two peaks (Fig. 4D) which may suggest the presence of a larger biomolecule dissociated in the ESI source or the presence of different stereoisomers or other spatial conformers. The second hypothesis seems to be more probable in view to two theoretically possible structures of the complex (glycine-like or histamine-like coordination, as shown in Fig. 5B). In order to get a deeper insight into the identity of this double peak, a similar chromatogram was recorded using ion-mobility MS detection. Fig. 6 demonstrates the presence of two $\mathrm{Pd}(\mathrm{His})_{2}$ forms with different collision cross sections (CCS). The ions are separated based on their differential mobility through a buffer gas. Ion mobility-mass spectrometry (IM-MS) can thus separate ions indistinguishable by mass spectrometry alone thereby enabling orthogonal specificity. Note that the synthetic Pd$\mathrm{His}_{2}$ complex gives only one peak at the retention time of the second peak observed in the sample. In the infusion mode, two forms with slightly different ion mobility can be, however, observed in the synthetic $\mathrm{Pd}(\mathrm{His})_{2}$ standard. These two forms are separated in the presence of a plant extract matrix, the species with a lower CCS (179.13 $\AA^{2}, 0.861 \mathrm{~V} \mathrm{~s} \mathrm{~cm}^{-2}$ ) eluting first (RT $25.0 \mathrm{~min}$ ) and that of higher mobility second (RT $26 \mathrm{~min}, 0.871 \mathrm{~V} \mathrm{~s}$ cm-2, CCS: $180.20 \AA^{2}$ ).
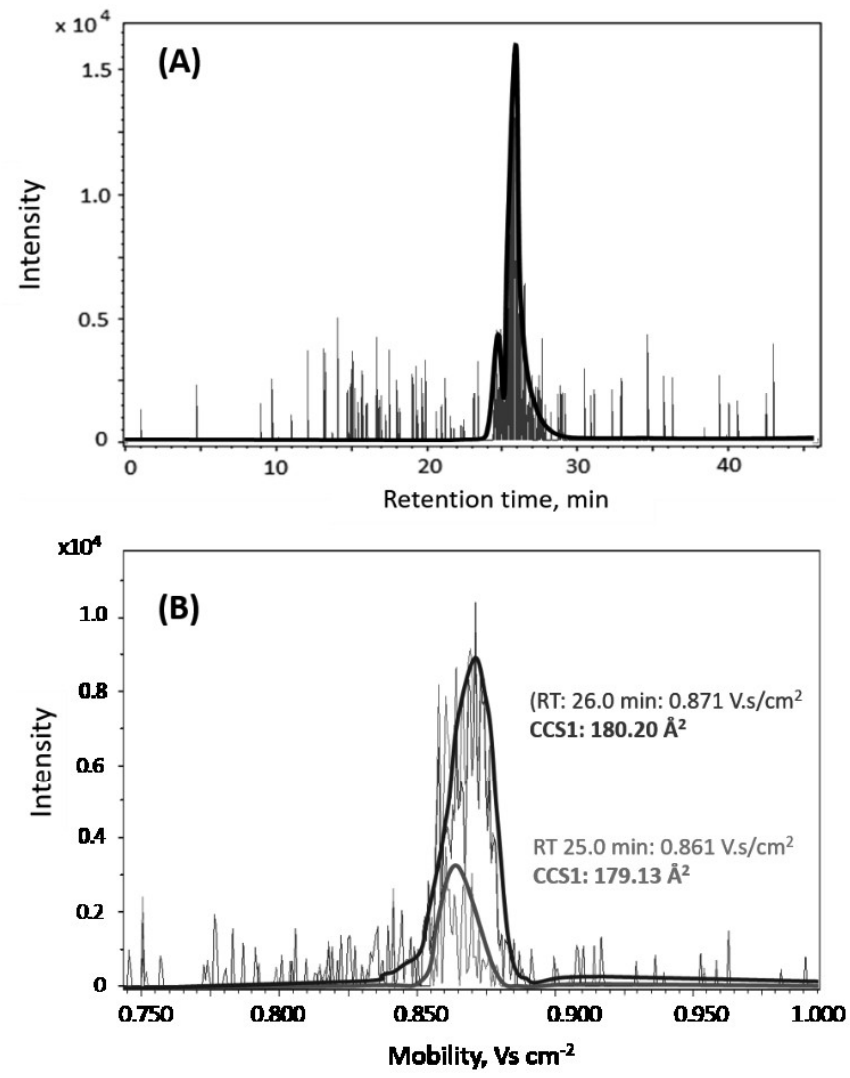

Figure 6. HILIC - ion-mobility MS investigation of $\mathrm{Pd}-\mathrm{His}_{2}$ complex in an extract of roots of Sinapis alba cultivated in the presence of $\mathrm{Pd}\left(\mathrm{NO}_{3}\right)_{2}$ : (A) XIC at $\mathrm{m} / \mathrm{z} 415.0341$ (B) ion mobilograms registered at the peaks appearing at $R T=25.0 \mathrm{~min}$ and $\mathrm{RT}=26.0 \mathrm{~min}$. 

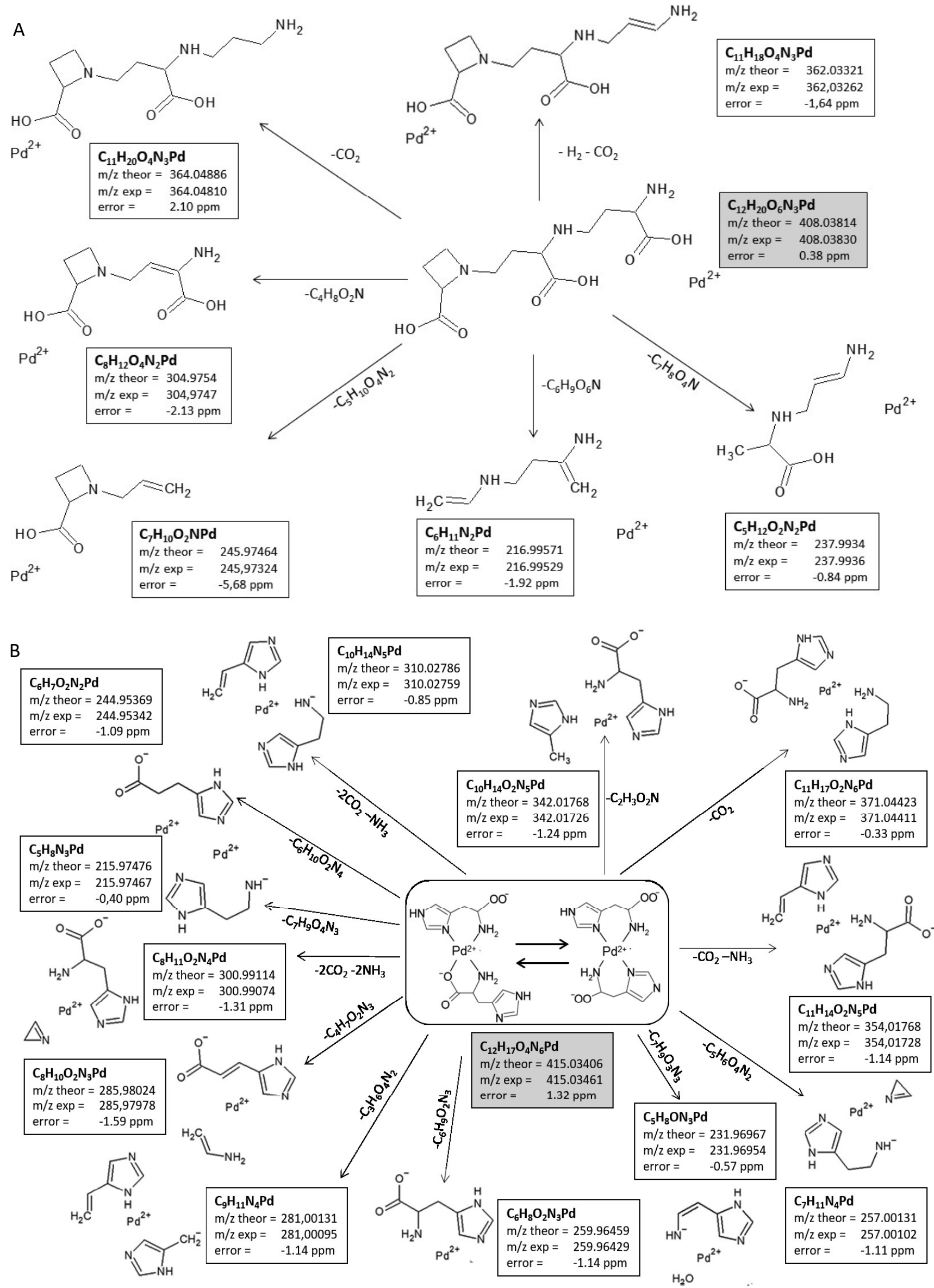

Figure 5. Fragmentation patterns in the MS/MS analysis of: A) Pd-nicotianamine complex; B) Pd(His)2 complex; 
Interestingly, a double peak in HILIC-MS was reported elsewhere for the Ni-staphylopine complex in the sample but not for the synthetic standard.29 Note the Pd-NA synthetic standard analysed by ionmobility produces only one peak. Therefore, in contrast to the $\mathrm{Pd}(\mathrm{His}) 2$ complex, the multiple peaks in the Pd-NA chromatogram (Fig. 4C) are produced by chemically distinctive species.

Histidine has three different metal-binding sites: carboxylate oxygen $\left(\mathrm{O}_{\text {caboxyl }}\right)$, imidazole imidonitrogen $\left(\mathrm{N}_{\mathrm{im}}\right)$ and aminonitrogen $\left(\mathrm{N}_{\mathrm{am}}\right)$ and is known to be the strongest ligand for metal co-ordination among all genetically encoded amino acids. ${ }^{30}$ Although the biosynthesis of histidine is metabolically expensive ${ }^{31}$, its metabolic cost is low compare to other known chelators (phytochelatins, nicotianamine) as it contains fewer atoms and does not require assimilation of sulphate. ${ }^{32}$ Therefore, His plays a substantial role in plant growth and in metal ion homeostasis in plants. ${ }^{32,33}$ It was shown elsewhere that histidine, together with citrates is highly involved in the detoxication process of $\mathrm{Ni}$ which shows many similarities to palladium. ${ }^{34}$ It was demonstrated that nickel transport depends on the level of histidine inside the root symplasm, where metal ions could be chelated and as such transferred to xylem. ${ }^{34}$ It was also observed that exogenous histidine applied on a plant resulted in the reduction of toxic effect of $\mathrm{Ni}^{35}$

\section{The role of the Pd-nicotianamine complex}

Nicotianamine is one of the well-known ligands responsible for metal binding in plant tissues. Nicotianamine complexes with zinc, nickel, copper and iron were identified in various plant species, as Lactuca sativa $\mathrm{L}^{12}$, Thlaspi ${ }^{36}$, Brassica carinata $^{37}$ and Arabidopsis ${ }^{38}$. Nicotianamine facilitates the transport of $\mathrm{Fe}(\mathrm{II})$ from phloem to organs instead of taking part in long-distance transport, as in the case of $\mathrm{Zn}{ }^{38}$ The results obtained by Callahan et al. show a strong correlation between Ni and NA concentrations in Thlaspi tissues. ${ }^{36}$. Data obtained in Brassica carinata shown induction of nicotianamine under $\mathrm{Cu}$ deficiency, what is in line with data concerning the role of nicotianamine in intracellular $\mathrm{Cu}$ delivery ${ }^{37}$. The high stability nicotianamine metal complexes would therefore suggest its role in dissolving $\mathrm{Pd}$ nanoparticles and in the transport of $\mathrm{Pd}$ ions in the plant.

\section{Conclusion}

Palladium, present at environmentally realistic concentrations, does not disturb the growth of Sinapis alba and does not cause significant morphological changes. It can be transported to the aerial part of the plant, but most of it remains in the roots. The exposure of Sinapis alba to palladium in the form of nanoparticles or $\mathrm{Pd}^{2+}$ ions is accompagnied by the synthesis of the $\mathrm{Pd}(\mathrm{His})_{2}$ complex in the roots which is also found in the stems but hardly in leaves. Another ligand associated with the chemistry of palladium in plants was demonstrated to be nicotianamine. Complexes of similar structure $\mathrm{Me}(\mathrm{His})_{2}$ and Me-NA were observed for plants treated with nickel compounds, where they are responsible for chelating metal ions for long-distance transport between organs. ${ }^{20,39} \mathrm{~A}$ number of other ligands, present in plant and able to bind $\mathrm{Pd}$, do not seem to intervene in the process of the reactivity of Sinapis alba towards the
Pd exposure. The study demonstrates the still largely unexplored potential of multidimensional HPLC with dual ICP MS and ESI MS/MS detection for in-vivo biological studies of metal-complexes.

\section{Conflicts of interest}

There are no conflicts to declare.

\section{Acknowledgements}

The study was supported by National Science Centre (NCN), PRELUDIUM: pre-doctoral grants, Poland, Grant No. 2014/ 15/ N/ NZ8/ 00326 and the EQUIPEX MARSS project (11-EQPX0027).

\section{Notes and references}

1 C. L. S. Wiseman, Z. Hassan Pour and F. Zereini, Chemosphere, 2016, 145, 61-67.

2 K. Ravindra, L. Bencs and R. Van Grieken, Sci. Total Environ., 2004, $318,1-43$.

3 K. Leopold, K. Wörle, R. Schindl, L. Huber, M. Maier and M. Schuster, Sci. Total Environ., 2017, 583, 169-175.

4 J. Schäfer, D. Hannker, J.-D. Eckhardt and D. Stüben, Sci. Total Environ., 1998, 215, 59-67.

5 N. Clément, B. Muresan, M. Hedde and D. François, Environ. Sci. Pollut. Res., 2015, 22, 20019-20031.

6 R. Sinha and S. k. Khare, in Bio-Nanoparticles, ed. O. V. Singh, John Wiley \& Sons, Inc, 2015, pp. 255-272.

7 J. Yang, W. Cao and Y. Rui, J. Plant Interact., 2017, 12, 158-169.

8 N. P. Bhatia, K. B. Walsh and A. J. M. Baker, J. Exp. Bot., 2005, 56, 1343-1349.

9 B. Leitenmaier and H. Küpper, Front. Plant Sci., 2013, 4, 374.

10 D. L. Callahan, A. J. M. Baker, S. D. Kolev and A. G. Wedd, JBIC J. Biol. Inorg. Chem., 2006, 11, 2-12.

11 A. Álvarez-Fernández, P. Díaz-Benito, A. Abadía, A.-F. LopezMillan and J. Abadía, Front. Plant Sci., 2014, 5, 105.

12 J. Wojcieszek, J. Jiménez-Lamana, K. Bierla, M. Asztemborska, L. Ruzik, M. Jarosz and J. Szpunar, J. Anal. At. Spectrom., 2019, 34, 683-693.

13 B. A. Leśniewska, J. Messerschmidt, N. Jakubowski and A. Hulanicki, Sci. Total Environ., 2004, 322, 95-108.

14 K. Kińska, J. Jiménez-Lamana, J. Kowalska, B. KrasnodębskaOstręga and J. Szpunar, Sci. Total Environ., 2018, 615, 1078-1085.

15 T. G. Appleton, Coord. Chem. Rev., 1997, 166, 313-359.

16 L. D. Pettit and M. Bezer, Coord. Chem. Rev., 1985, 61, 97-114.

17 B. Stypinski-Mis and G. Anderegg, Anal. Chim. Acta, 2000, 406, 325-332.

18 J. Szpunar and R. Łobiński, Fresenius J. Anal. Chem., 1999, 363, 550-557.

19 R. Lobinski, J. S. Becker, H. Haraguchi and B. Sarkar, Pure Appl. Chem., 2010, 82, 493-504.

20 P. Flis, L. Ouerdane, L. Grillet, C. Curie, S. Mari and R. Lobinski, New Phytol., 2016, 211, 1129-1141.

21 M. Navarro-Reig, J. Jaumot, B. Piña, E. Moyano, M. T. Galceran and R. Tauler, Metallomics, 2017, 9, 660-675.

22 L. Ouerdane, S. Mari, P. Czernic, M. Lebrun and R. Łobiński, J. Anal. At. Spectrom., 2006, 21, 676-683. 
23 R. Mazur, M. Sadowska, Ł. Kowalewska, A. Abratowska, H. M. Kalaji, A. Mostowska, M. Garstka and B. Krasnodębska-Ostręga, BMC Plant Biol., 2016, 16, 191.

24 M. Ronchini, L. Cherchi, S. Cantamessa, M. Lanfranchi, A. Vianelli, P. Gerola, G. Berta and A. Fumagalli, Environ. Sci. Pollut. Res., 2015, 22, 7600-7611.

25 F. Battke, K. Leopold, M. Maier, U. Schmidhalter and M. Schuster, Plant Biol., 2008, 10, 272-276.

26 F. Alt, G. Weber, J. Messerschmidt, A. von Bohlen, B. Kastenholz and K. Guenther, Anal. Lett., 2002, 35, 1349-1359.

27 G. Weber, J. Messerschmidt, A. von Bohlen, B. Kastenholz and K. Günther, ELECTROPHORESIS, 2004, 25, 1758-1764.

28 B. Buszewski and S. Noga, Anal. Bioanal. Chem., 2012, 402, 231247.

29 G. Ghssein, C. Brutesco, L. Ouerdane, C. Fojcik, A. Izaute, S. Wang, C. Hajjar, R. Lobinski, D. Lemaire, P. Richaud, R. Voulhoux, A. Espaillat, F. Cava, D. Pignol, E. Borezée-Durant and P. Arnoux, Science, 2016, 352, 1105-1109.

30 P. Deschamps, P. P. Kulkarni, M. Gautam-Basak and B. Sarkar, Coord. Chem. Rev., 2005, 249, 895-909.

31 R. A. Ingle, Arab. Book Am. Soc. Plant Biol., 2011, 9, e0141.

32 A. Stepansky and T. Leustek, Amino Acids, 2006, 30, 127-142.

33 R. Muralla, C. Sweeney, A. Stepansky, T. Leustek and D. Meinke, Plant Physiol., 2007, 144, 890-903.

34 L. Kerkeb and U. Krämer, Plant Physiol., 2003, 131, 716-724.

35 J. P. F. D'Mello, Amino Acids in Higher Plants, CABI, 2015.

36 D. L. Callahan, S. D. Kolev, R. A. J. O'Hair, D. E. Salt and A. J. M. Baker, New Phytol., 2007, 176, 836-848.

37 B. Irtelli, W. A. Petrucci and F. Navari-Izzo, J. Exp. Bot., 2009, 60, 269-277.

38 M. Schuler, R. Rellán-Álvarez, C. Fink-Straube, J. Abadía and P. Bauer, Plant Cell, 2012, 24, 2380-2400.

39 J. Meng, W. Zhang, C.-X. Cao, L.-Y. Fan, J. Wu and Q.-L. Wang, Analyst, 2010, 135, 1592-1599. 


\section{Supplementary information}

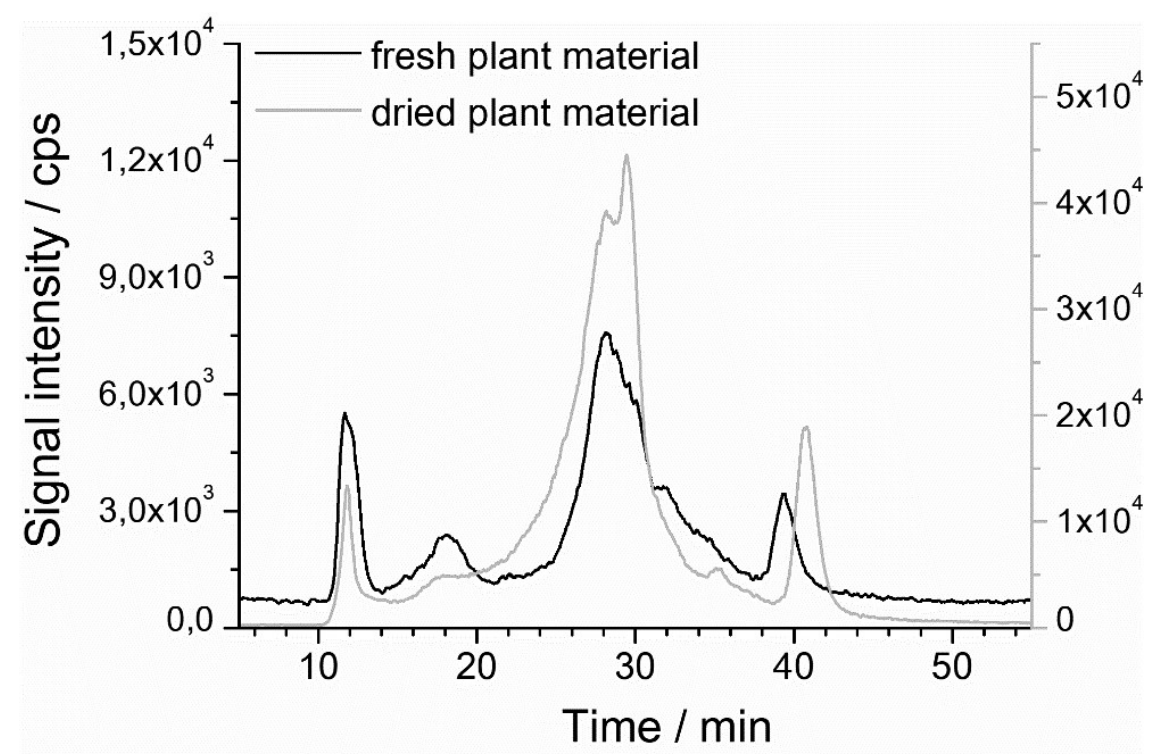

Figure 1 SI. SEC ICP MS chromatograms of lyophilized fresh plant extract (black line) and dried tissue extract (light grey line, secondary Y-axis). Chromatograms were obtained on SEC Superdex-200 column after injection of $100 \mu \mathrm{L}$ of the sample and isocratic elution with ammonium acetate $(\mathrm{pH} 7.5)$ at a flow rate of $0.7 \mathrm{~mL} \mathrm{~min}^{-1}$.

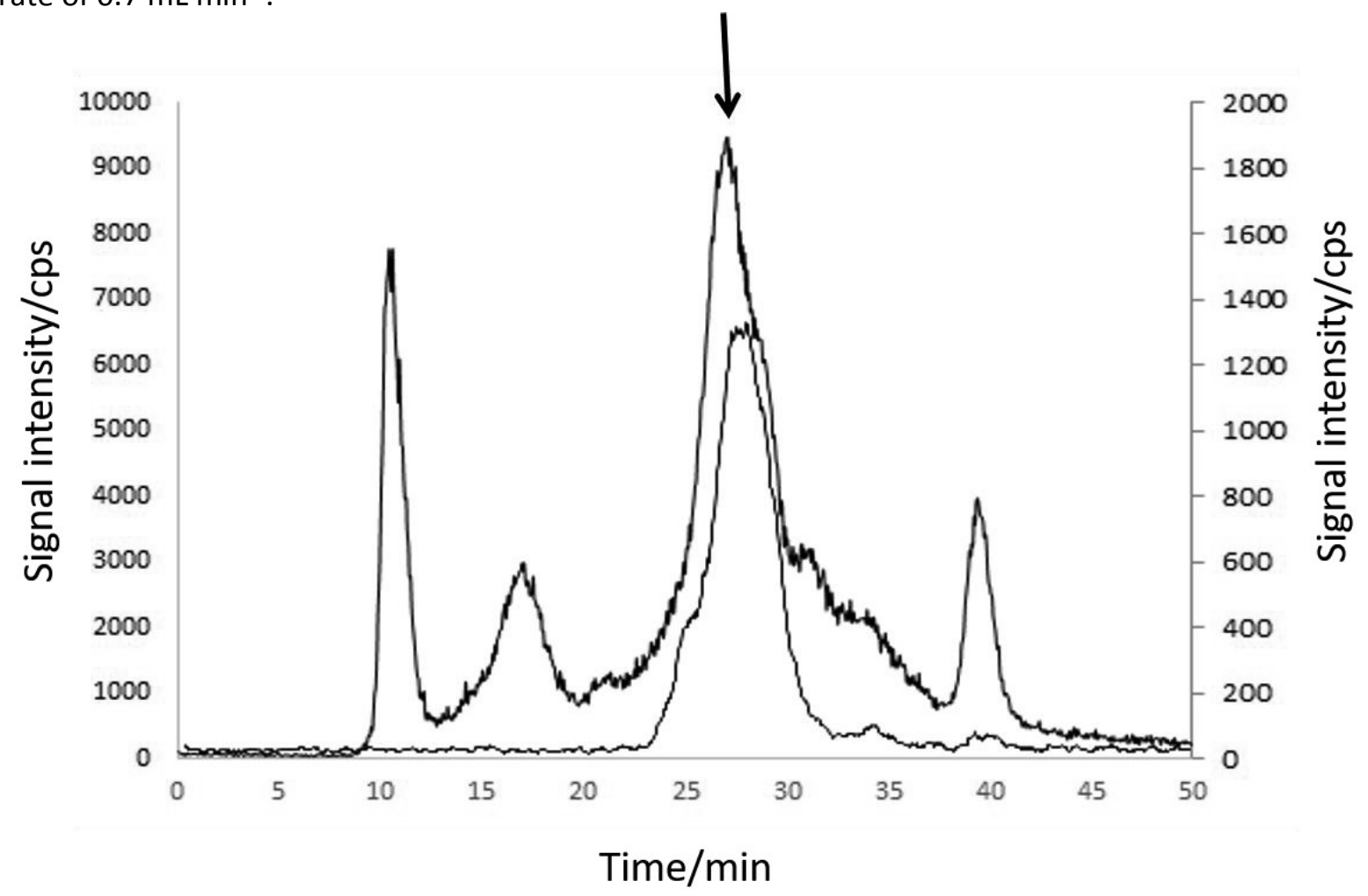

Figure 2 SI. Confirmation of the species stability upon lyophilisation: SEC ICP MS chromatograms of the root extract and lyophilized and dissolved fraction of interest (marked with an arrow) Chromatograms were obtained on SEC Superdex-200 column after injection of $100 \mu \mathrm{L}$ of the sample and isocratic elution with ammonium acetate $(\mathrm{pH} \mathrm{7.5)}$ at a flow rate of $0.7 \mathrm{~mL} \mathrm{~min}^{-1}$. 


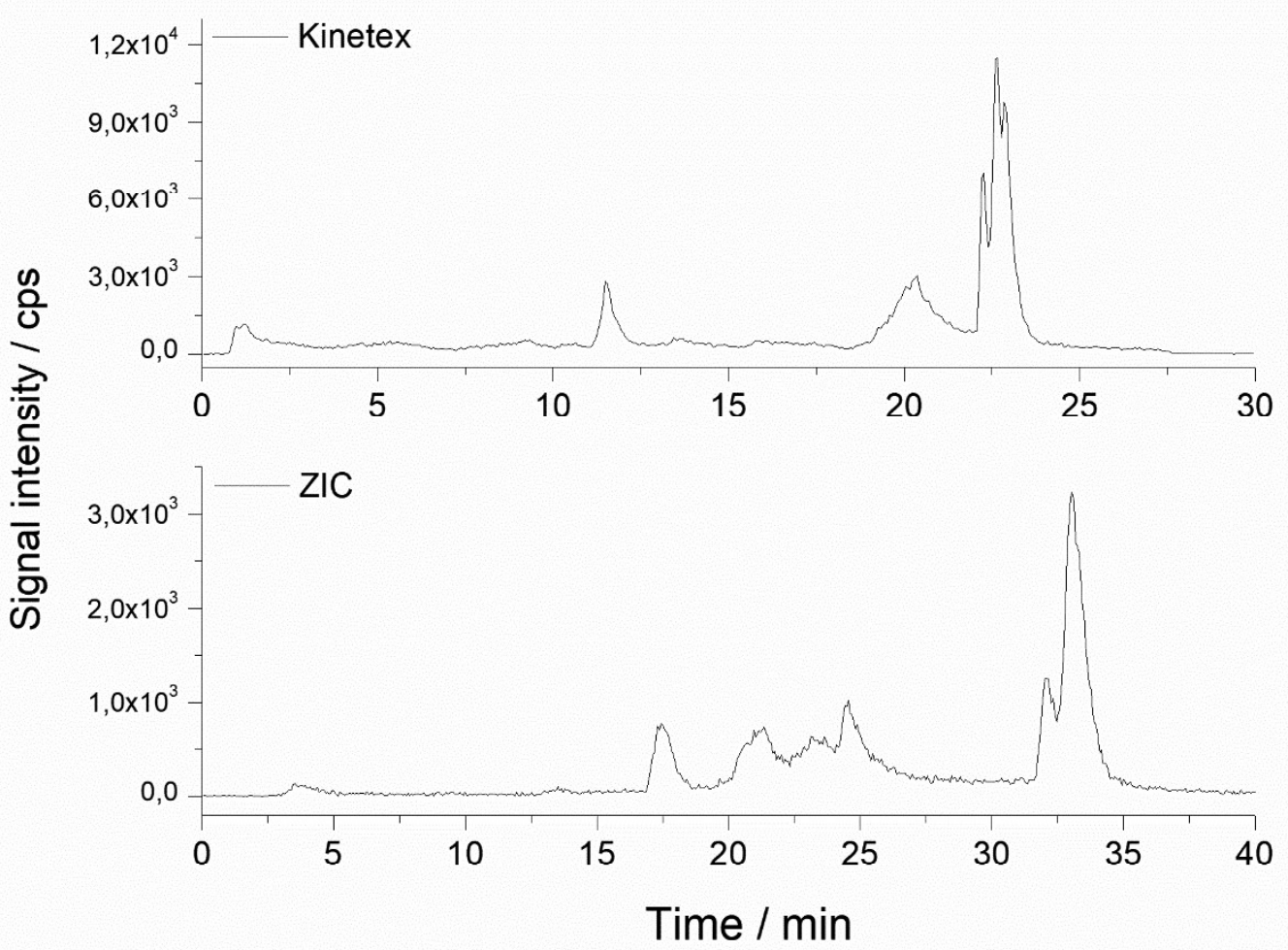

Figure 3 SI. Effect of the choice of the HILIC stationary phase on fractionation efficiency of the plant extract size-exclusion fraction as in Fig. 3d. a) Kinetex column; b) ZIC column. See procedure for the optimum experimental conditions.

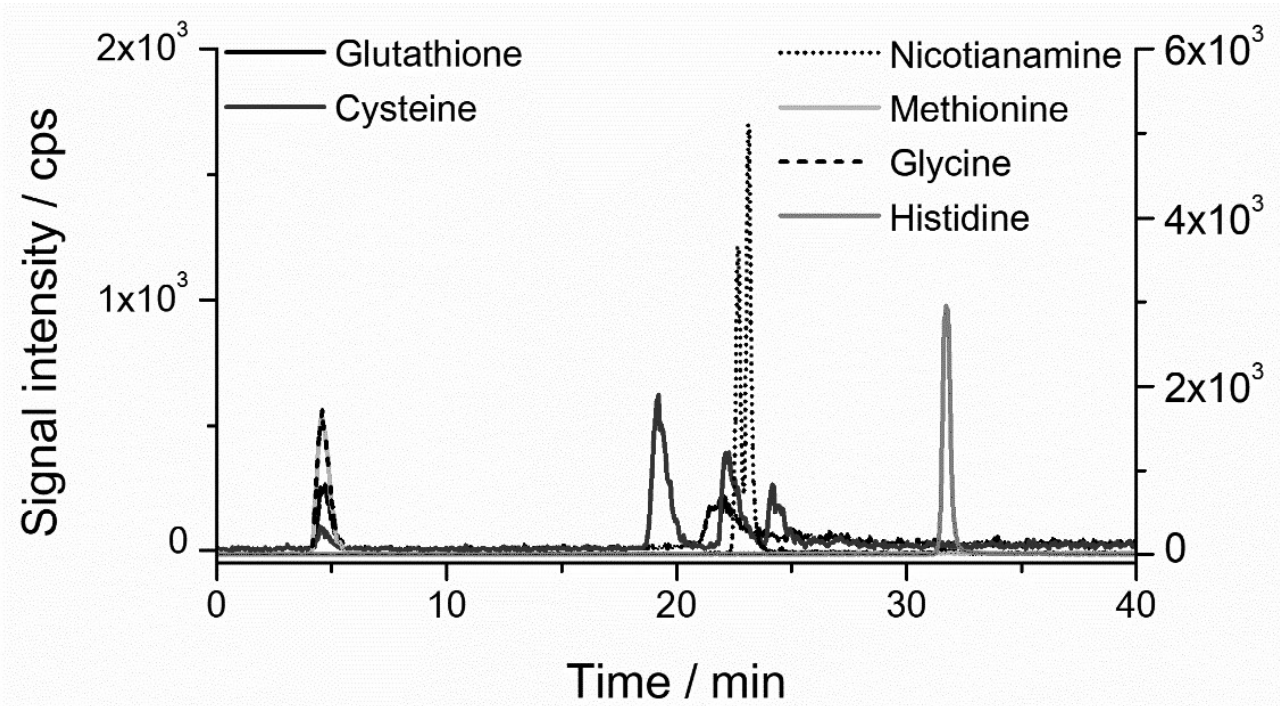

Figure 4 SI. HILIC -ICP MS chromatograms of model palladium complexes with reduced glutathione (GSH), histidine (His), cysteine (Cys), glycine (Gly) and methionine (Met). ZicColumn. Injection of $4 \mu \mathrm{L}$ of the sample, gradient elution with a mixture of ammonium acetate $(\mathrm{pH} 5.5)$ and acetonitrile a flow rate of $0.2 \mathrm{~mL} \mathrm{~min}^{-1}$. 